\title{
Diastolic Left Ventricular Function in Relation to Circulating Metabolic Biomarkers in a General Population
}

Zhen-Yu Zhang, MD;* Vannina G. Marrachelli, PhD;* Lutgarde Thijs, MSc; Wen-Yi Yang, MD; Fang-Fei Wei, MD; Daniel Monleon, PhD; Lotte Jacobs, PhD; Tim Nawrot, PhD; Peter Verhamme, MD, PhD; Jens-Uwe Voigt, MD, PhD; Tatiana Kuznetsova, MD, PhD; Josep Redón, MD, PhD; Jan A. Staessen, MD, PhD

Background-The metabolic signature associated with subclinical diastolic left ventricular (LV) dysfunction in the population remains ill defined.

Methods and Results - In 711 randomly recruited Flemish (50.8\% women; mean age, 50.8 years), we assessed echocardiographic Doppler indexes of diastolic LV function in relation to 44 circulating metabolites determined by nuclear magnetic resonance spectroscopy. In multivariable-adjusted regression analysis with Bonferroni correction of significance levels applied, peak a' decreased $(P \leq 0.048)$ and $e^{\prime} / a^{\prime}$ increased $(P \leq 0.044)$ with circulating tyrosine, high-density lipoprotein apolipoproteins, glucose+glutamine, and an unidentified molecule. Effect sizes expressed per 1-SD increment in the metabolite ranged from -0.277 to $-0.203 \mathrm{~cm} / \mathrm{s}$ for peak a' and from +0.047 to +0.054 for e'/a'. In addition, peak a' decreased $(P \leq 0.031)$ with glucose+2-aminobutyrate $(-0.261 \mathrm{~cm} / \mathrm{s})$ and glucose+2-phosphoglycerate $(-0.209 \mathrm{~cm} / \mathrm{s})$. In partial least square discriminant analysis (PLS-DA), metabolites associated with normal diastolic LV function $(n=538)$ included glucose+glutamine, glucose+2aminobutyrate, and glucose+2-phosphoglycerate, whereas those siding with abnormal function encompassed 4-aminobutyrate, 4-hydroxybutyrate, creatinine, and phosphocholine. In receiver operating characteristics plots, adding 3 latent factors identified by PLS-DA to prohormone brain natriuretic peptide increased $(P<0.0001)$ the area under the curve from $0.64(95 \% \mathrm{Cl}, 0.58-0.68)$ to $0.73(0.68-0.78)$.

Conclusions - In a general population, circulating metabolites indicative of energy substrate utilization and protection against oxidative stress differentiated normal from abnormal diastolic LV function. These findings improve our understanding of the pathophysiology underlying deterioration of diastolic LV function and potentially point to new targets for prevention and treatment of this condition. (J Am Heart Assoc. 2016;5:e002681 doi: 10.1161/JAHA.115.002681)

Key Words: biomarker • diastolic left ventricular function • metabolomics • nuclear magnetic resonance spectroscopy • population science

$\mathrm{P}$ revalence of heart failure (HF) among adults living in Europe amounts to 15 million $^{1}$ and 5 million in the United States, ${ }^{2}$ of whom approximately half have diastolic HF with a 5 -year mortality rate in excess of $50 \%{ }^{1,3}$ In population studies, ${ }^{4-6}$ frequency of asymptomatic diastolic left ventric-

ular (LV) dysfunction, as diagnosed by echocardiography, is as high as $27 \%$. Availability of biomarkers helping to understand the underlying pathophysiology and identify the large pool of individuals with subclinical diastolic LV dysfunction at high risk of $\mathrm{HF}$ is key to prevention and timely treatment. ${ }^{1}$

From the Studies Coordinating Centre, Research Unit Hypertension and Cardiovascular Epidemiology (Z.-Y.Z., L.T., W.-Y.Y., F.-F.W., L.J., T.K., J.A.S.), Centre for Molecular and Vascular Biology (P.V.), and Research Unit Cardiology (J.-U.V.), KU Leuven Department of Cardiovascular Sciences, University of Leuven, Belgium; Metabolomic and Molecular Image Laboratory, Fundación Investigatión Clínico de Valencia (INCLIVA), Valencia, Spain (V.G.M., D.M., J.R.); Centre for Environmental Sciences, University of Hasselt, Diepenbeek, Belgium (T.N.); Research Unit Environment and Health, KU Leuven Department of Public Health and Primary Care, University of Leuven, Belgium (T.N.); Hypertension Unit, Division of Internal Medicine, Hospital Clinico, University of Valencia, Spain (J.R.); Centro de Investigación Biomédica de la Fisiopatología de la Obesidad y la Nutrición (CIBERObn), Madrid, Spain (J.R.); Instituto de Salud Carlos III, Madrid, Spain (J.R.); R \& D Group VitaK, Maastricht University, Maastricht, The Netherlands (J.A.S.).

${ }^{*} \operatorname{Dr}$ Zhang and Dr Marrachelli are joint first authors who contributed equally to this work.

Correspondence to: Jan A. Staessen, MD, PhD, Studies Coordinating Centre, Research Unit Hypertension and Cardiovascular Epidemiology, KU Leuven Department of Cardiovascular Sciences, University of Leuven, Campus Sint Rafaël, Kapucijnenvoer 35, Box 7001, BE-3000 Leuven, Belgium. E-mails: jan.staessen@med. kuleuven.be, ja.staessen@maastrichtuniversity.nl

Received September 23, 2015; accepted February 19, 2016.

(c) 2016 The Authors. Published on behalf of the American Heart Association, Inc., by Wiley Blackwell. This is an open access article under the terms of the Creative Commons Attribution-NonCommercial License, which permits use, distribution and reproduction in any medium, provided the original work is properly cited and is not used for commercial purposes. 
Metabolomics is the systematic study of small-molecule metabolite profiles in biological fluids. ${ }^{7,8}$ Studies of HF patients matched with healthy controls showed a different metabolic signature in serum ${ }^{9}$ and urine. ${ }^{9,10}$ Recently, Cheng et al. demonstrated that over and beyond classical risk factors and Btype natriuretic peptide (BNP), circulating plasma metabolites had diagnostic value in assessing HF-related metabolic disturbances and predicting hospitalizations and mortality. ${ }^{8}$ However, the utility of metabolite profiling in HF remains uncertain. ${ }^{11}$ Findings in symptomatic patients cannot be extrapolated to subclinical disease, in which biomarkers would have the greatest diagnostic or prognostic meaning. ${ }^{12}$ In keeping with these considerations, ${ }^{11,12}$ we examined the metabolic signature of diastolic LV dysfunction in a random population sample enrolled in the Flemish Study on Environment, Genes and Health Outcomes (FLEMENGHO). ${ }^{13}$

\section{Methods}

\section{Study Participants}

The Ethics Committee of the University of Leuven approved FLEMENGHO protocol. ${ }^{13}$ Recruitment started in 1985 and continued until 2004. The initial participation rate was $78.0 \%$.

Table 1. Characteristics of 711 Participants by Diastolic LV Function Class

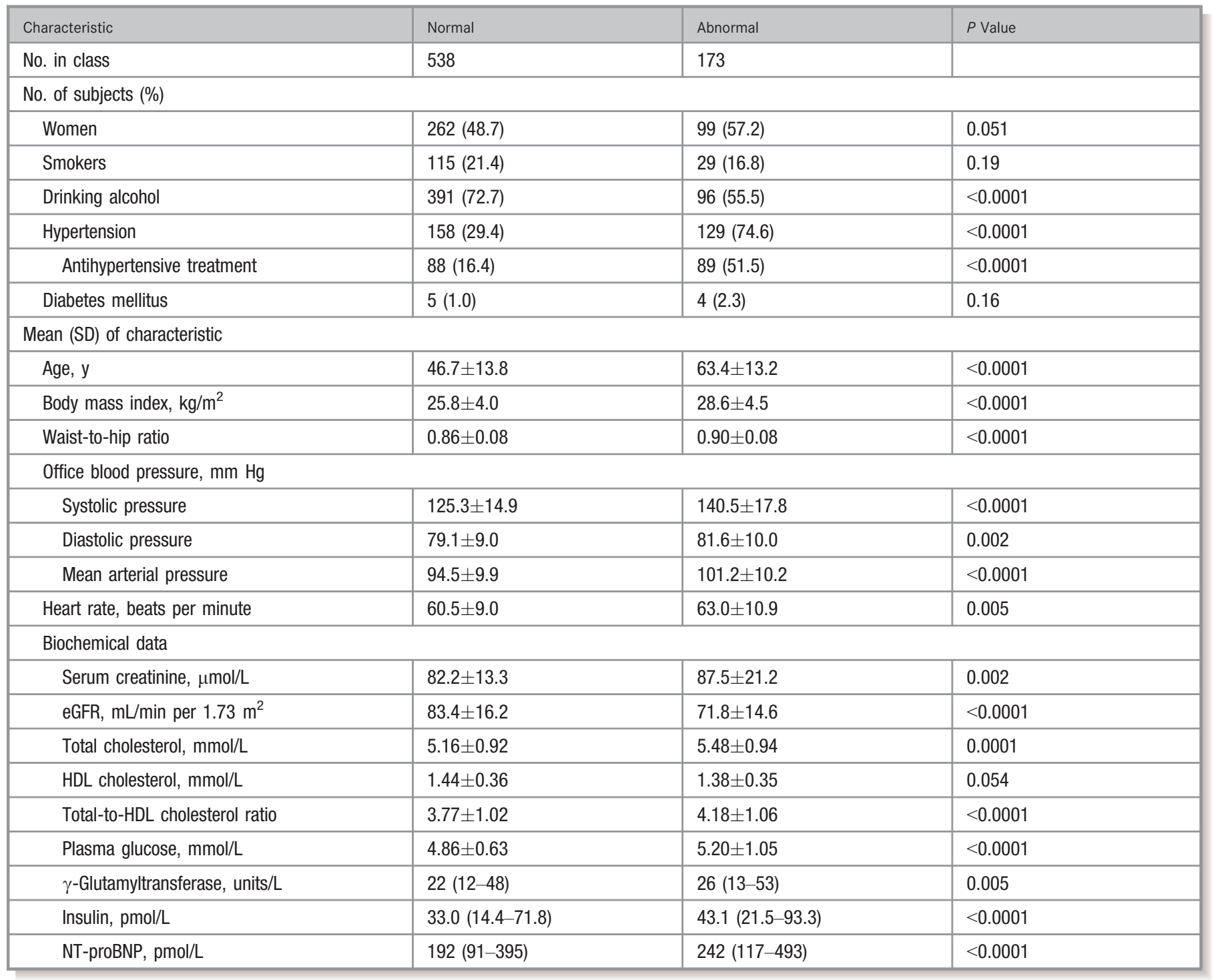

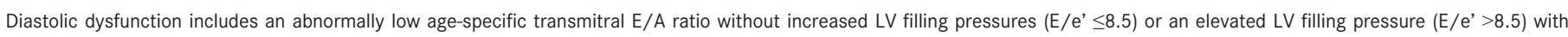

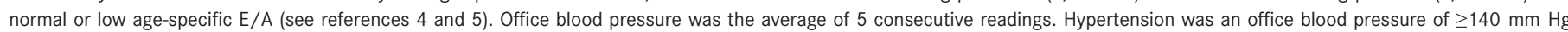

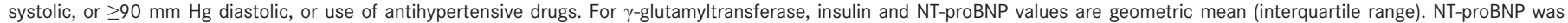

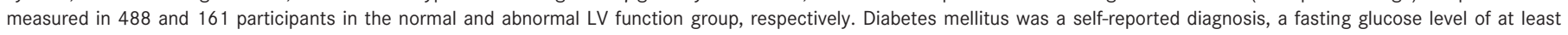

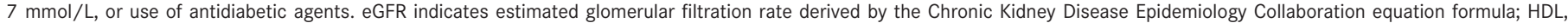
high-density lipoprotein; LV, left ventricular; NT-proBNP, N-terminal of the prohormone brain natriuretic peptide; 
Table 2. Echocardiographic Measurements by Diastolic LV Function Class

\begin{tabular}{|c|c|c|}
\hline Characteristic & Normal & Abnormal \\
\hline Number in class & 538 & 173 \\
\hline \multicolumn{3}{|l|}{ Conventional echocardiography } \\
\hline Left atrial volume, $\mathrm{mL}$ & $41.2 \pm 12.4$ & $48.1 \pm 15.5$ \\
\hline Left atrial volume index, $\mathrm{mL} / \mathrm{m}^{2}$ & $21.9 \pm 5.40$ & $26.0 \pm 7.54$ \\
\hline Left ventricular mass, $\mathrm{g}$ & $166.8 \pm 44.9$ & $194.6 \pm 56.8$ \\
\hline Left ventricular mass index, $\mathrm{g} / \mathrm{m}^{2}$ & $88.8 \pm 19.1$ & $104.5 \pm 25.5$ \\
\hline \multicolumn{3}{|l|}{ Doppler data } \\
\hline Deceleration time, ms & $160.2 \pm 31.0$ & $190.2 \pm 44.0$ \\
\hline Isovolumetric relaxation time, ms & $94.4 \pm 14.0$ & $107.2 \pm 18.6$ \\
\hline E peak, $\mathrm{cm} / \mathrm{s}$ & $77.3 \pm 14.9$ & $68.2 \pm 17.2$ \\
\hline A peak, $\mathrm{cm} / \mathrm{s}$ & $59.1 \pm 13.9$ & $82.3 \pm 15.7$ \\
\hline E/A ratio & $1.39 \pm 0.46$ & $0.85 \pm 0.24$ \\
\hline e' peak, cm/s & $12.6 \pm 3.26$ & $7.80 \pm 1.95$ \\
\hline a' peak, cm/s & $9.78 \pm 2.11$ & $11.1 \pm 1.92$ \\
\hline e'/a' ratio & $1.42 \pm 0.66$ & $0.73 \pm 0.26$ \\
\hline E/e' ratio & $6.38 \pm 1.35$ & $9.13 \pm 2.74$ \\
\hline
\end{tabular}

Diastolic dysfunction includes an abnormally low age-specific transmitral E/A ratio without increased LV filling pressures $\left(E / e^{\prime} \leq 8.5\right)$ or an elevated LV filling pressure $\left(E / e^{\prime}\right.$ $>8.5$ ) with normal or low age-specific $\mathrm{E} / \mathrm{A}$ (see references 4 and 5). By definition, all $P$ values for the between-group differences were significant. LV indicates left ventricular.

Participants were repeatedly followed up. ${ }^{13}$ From May 2005 until May 2010, we mailed an invitation letter to 1208 former participants for a follow-up examination. However, 153 were unavailable because they had died $(n=26)$, had been institutionalized or were too ill ( $n=27)$, or had moved out of the area $(n=100)$. Of the remaining 1055 former participants, 828 renewed informed consent. At the stage of re-examination, the participation rate was therefore 78.5\%. We excluded 117 participants from analysis because serum samples were unavailable $(n=96)$, metabolites had extreme values dissociated from the distribution $(n=3)$, atrial fibrillation or paced heart rhythm made assessment of diastolic LV function impossible $(n=7)$, or poor echocardiographic image quality $(n=11)$. Thus, the number of participants statistically analyzed totaled 711.

\section{Echocardiography}

\section{Data acquisition}

One observer (T.K.) did the ultrasound examination, ${ }^{4}$ using a Vivid7 Pro (GE Vingmed, Horten, Norway) device interfaced with a 2.5- to 3.5-MHz phased-array probe. For offline analysis, she recorded at least 5 heart cycles according to the recommendations of the American Society of Echocardiography. ${ }^{14}$ M-mode echocardiograms of the left ventricle were recorded from the parasternal long-axis view under control of the 2-dimensional image. The ultrasound beam was positioned just below the mitral valve at the level of the posterior tendinous chords. To record mitral and pulmonary vein (PV) flow velocities from the apical window, the observer positioned the Doppler sample volume at the mitral valve tips, in the right superior PV, and between the LV outflow and mitral inflow, respectively. From the apical window, the observer positioned a 5-mm Doppler sample at the septal, lateral, inferior, and posterior sites of the mitral annulus to record low-velocity, high-intensity myocardial signals at a high frame rate (>190 frames per second), while ensuring parallel alignment of the ultrasound beam with the myocardial segment of interest.

\section{Off-line analysis}

One reader (T.K.) analyzed the digitally stored images, averaging 3 heart cycles, using a workstation running EchoPac software (version 4.0.4; GE Vingmed, Horten, Norway). LV internal diameter and interventricular septal and posterior wall thickness were measured at end-diastole from the 2-dimensionally guided M-mode tracing. When optimal orientation of M-mode ultrasound beam could not be obtained, the reader performed linear measurements on correctly oriented 2-dimensional (2D) images. End-diastolic LV dimensions were used to calculate LV mass by an anatomically validated formula. ${ }^{14}$ Left atrial (LA) volume was calculated using the prolate-elipsoid method from the LA dimensions in 3 orthogonal planes and indexed to body surface area. ${ }^{14}$ From the transmitral flow signal, the reader determined peak early diastolic velocity (E), peak late diastolic velocity (A), E/A ratio, and transmitral A flow duration. From the PV flow signal, she measured the duration of PV reversal flow during atrial systole (AR). From the tissue Doppler imaging recordings, the reader measured peak early (e') and peak late (a') diastolic mitral annular velocities, and the e'/a' ratio at the 4 acquisition sites (septal, lateral, inferior, and posterior).

Intraobserver reproducibility was the 2-SD interval about the mean of the relative differences across pair-wise readings. Intraobserver reproducibility for the tissue Doppler peak velocities across the 4 sampling sites ranged from $4.5 \%$ to $5.3 \%$ for e' and from $4.0 \%$ to $4.5 \%$ for a' ${ }^{4}$ Reproducibility was $2.2 \%$ for internal end-diastolic LV diameter, $4.6 \%$ for LV wall thickness, and $4.3 \%$ for LV mass. ${ }^{15}$

We dichotomized diastolic LV function into normal and abnormal as described in previous publications. ${ }^{4,5}$ Diastolic dysfunction included: (1) patients with an abnormally low agespecific transmitral $E / A$ ratio indicative of impaired relaxation, but without evidence of increased LV filling pressures (E/e' $\leq 8.5)$; (2) patients with mildly to moderately elevated LV filling pressure $\left(E / e^{\prime}>8.5\right)$ and an $E / A$ ratio within the normal age-specific range; and (3) and patients with an elevated $E / e^{\prime}$ 
Table 3. List of Plasma Metabolic Biomarkers

\begin{tabular}{|c|c|}
\hline Amino Acids & $1 \mathrm{H}$ Shift \\
\hline 2-Aminobutyrate (C4H9NO2) & 1.86 \\
\hline 4-Aminobutyrate (C4H9NO2) & 3.00 \\
\hline Alanine (C3H7N02) & 1.46 \\
\hline Aspartate (C4H7N04) & 2.81 \\
\hline Glutamate (C5H9N04) & 2.36 \\
\hline Glycine (C2H5N02) & 3.55 \\
\hline Glutamine (C5H10N203) & 2.42 \\
\hline Isoleucine (C6H13N02) & 1.00 \\
\hline Leucine (C6H13N02) & 1.71 \\
\hline Phenylalanine (C9H11NO2) & 3.26 \\
\hline Threonine (C4H9N03) & 3.58 \\
\hline Tyrosine (C9H11N03) & 6.88 \\
\hline Valine (C5H11N02) & 0.97 \\
\hline Lipids & $1 \mathrm{H}$ Shift \\
\hline Fatty acids with $\alpha-\mathrm{CH} 2$ & 2.23 \\
\hline Fatty acids with (-CH2-)n & 1.25 \\
\hline Fatty acids with $=\mathrm{CH}-\mathrm{CH} 2-\mathrm{CH} 2=+$ citrate & 2.69 \\
\hline Fatty acids with $-\mathrm{CH} 3$ & 0.84 \\
\hline Fatty acids with $=\mathrm{CH}-\mathrm{CH} 2-\mathrm{CH} 2-$ & 2.00 \\
\hline Fatty acids with $-\mathrm{CH}=\mathrm{CH}$ & 5.31 \\
\hline HDL apolipoproteins & 6.50 \\
\hline Cholesterol (C27H460) & 0.66 \\
\hline Valerate (C5H1002) & 1.28 \\
\hline Fatty acids with $\beta$-CH2 & 1.57 \\
\hline 3-Hydroxybutyrate (C4H803) & 1.20 \\
\hline Carbohydrates & $1 \mathrm{H}$ Shift \\
\hline$\alpha$-Glucose (C6H1206) & 5.23 \\
\hline Glucose+taurine (C6H1206+C2H7N03S) & 3.24 \\
\hline Glucose (C6H1206) & 3.47 \\
\hline Glycoprotein & 2.04 \\
\hline Organic Acids & 1H Shift \\
\hline Acetate $(\mathrm{C} 2 \mathrm{H} 402)$ & 1.91 \\
\hline 4-Hydroxybutyrate (C4H803) & 1.78 \\
\hline Lactate (C3H603) & 1.33 \\
\hline 2-0xobutyrate (C4H603) & 2.75 \\
\hline Other Metabolites & $1 \mathrm{H}$ Shift \\
\hline Creatinine (C4H7N30) & 4.05 \\
\hline Choline (C5H14N0) & 3.21 \\
\hline Ethanolamine (C2H7NO) & 3.41 \\
\hline Trimethylamine (C3H9N) & 3.37 \\
\hline Glycerol (C3H803) & 3.61 \\
\hline
\end{tabular}

Continued
Table 3. Continued

\begin{tabular}{|l|l|}
\hline Other Metabolites & $1 \mathrm{H}$ Shift \\
\hline Ethanol (C2H60) & 3.64 \\
\hline $\begin{array}{l}\text { Creatine+creatine-phosphate } \\
\text { (C4H9N302+C4H10N305P) }\end{array}$ & 3.92 \\
\hline Phosphocholine (C5H15N04P) & 3.22 \\
\hline Glucose+2-aminobutyrate (C6H1206+C4H9N02) & 3.72 \\
\hline Glucose+glutamine (C6H1206+C5H10N203) & 3.78 \\
\hline Glucose+2-phosphoglycerate (C6H1206+C3H707P) & 3.80 \\
\hline Unknown molecule & 3.87 \\
\hline
\end{tabular}

HDL indicates high-density lipoprotein.

ratio and an abnormally low age-specific E/A ratio (combined dysfunction). To confirm elevation of LV filling pressure, the reader of the offline echocardiographic images checked the differences in the duration between the transmitral A flow (Ad) and the reverse flow in the pulmonary veins (ARd) during atrial systole $(A d<A R d+10)$ and the left atrial volume index $\left(\geq 28 \mathrm{~mL} / \mathrm{m}^{2}\right)$.

\section{Nuclear Magnetic Resonance Spectroscopy}

For nuclear magnetic resonance (NMR) spectroscopy, ${ }^{7,16,17}$ $500 \mu \mathrm{L}$ of plasma were mixed with $50 \mu \mathrm{L}$ of $\mathrm{D}_{2} \mathrm{O}$ (as a field lock). A total of $500 \mu \mathrm{L}$ of the mixture of each sample was then individually transferred into a 5-mm high-resolution NMR tube. All proton NMR ( ${ }^{1} \mathrm{H}$ NMR) spectra were acquired using a standard 1-dimensional pulse sequence with water suppression (Bruker Avance 600 spectrometer operating at $600.13 \mathrm{MHz}$ with a $5-\mathrm{mm} 1 \mathrm{H} / 13 \mathrm{C} / 15 \mathrm{~N}$ TXI probe). A total of 256 FIDs (free induction decay) were collected into $64 \mathrm{k}$ data points with a spectral width of $14 \mathrm{ppm}$ and a recycle delay (RD) of 1 second. The water signal was saturated with weak irradiation during the RD. Before Fourier transformation, the FID was multiplied by a $0.3-\mathrm{Hz}$ exponential line broadening.

Spectral chemical shift referencing on the alanine $\mathrm{CH} 3$ doublet signal at $1.475 \mathrm{ppm}$ was performed in all spectra. Resonances in these spectral regions were assigned using the literature ${ }^{18}$ and selected 2D NMR (especially for long chain metabolites) spectra. We normalized all spectra to total spectral area. Thus, individual peak intensities were normalized to total metabolite content for a better comparison between samples. Spectral regions belonging to EDTA resonances (2.52-2.57 and 3.06-3.17 ppm) were removed from spectra for subsequent analysis. We used available spectral databases and 2D NMR experiments to aid structural identification of relevant metabolites. All spectra were processed using Topspin 1.3 (Bruker Biospin $\mathrm{GmbH}$, Rheinstetten, Germany) and transferred to MATLAB (2006; The MathWorks, Inc., Natick, 
Table 4. Levels of Metabolic Biomarkers by Diastolic LV Function Class

\begin{tabular}{|c|c|c|c|}
\hline Metabolic Biomarker & $\begin{array}{l}\text { Normal } \\
(n=538)\end{array}$ & $\begin{array}{l}\text { Abnormal } \\
(n=173)\end{array}$ & $P$ Value \\
\hline \multicolumn{4}{|l|}{ Amino acids } \\
\hline 2-Aminobutyrate & $17.7 \pm 1.09$ & $17.4 \pm 0.82$ & 0.0003 \\
\hline 4-Aminobutyrate & $6.97 \pm 0.50$ & $6.80 \pm 0.50$ & 0.0001 \\
\hline Alanine & $12.3 \pm 0.63$ & $12.2 \pm 0.51$ & 0.0058 \\
\hline Aspartate & $5.46 \pm 0.73$ & $5.46 \pm 0.58$ & 0.95 \\
\hline Glutamate & $9.26 \pm 1.12$ & $9.06 \pm 0.77$ & 0.0088 \\
\hline Glycine & $1.28 \pm 0.16$ & $1.29 \pm 0.16$ & 0.62 \\
\hline Glutamine & $10.4 \pm 1.48$ & $10.2 \pm 1.18$ & 0.018 \\
\hline Isoleucine & $12.6 \pm 0.59$ & $12.5 \pm 0.57$ & 0.075 \\
\hline Leucine & $33.4 \pm 2.51$ & $32.7 \pm 1.86$ & 0.0002 \\
\hline Phenylalanine & $2.92 \pm 0.62$ & $2.91 \pm 0.58$ & 0.83 \\
\hline Threonine & $2.31 \pm 0.27$ & $2.35 \pm 0.24$ & 0.098 \\
\hline Tyrosine & $2.36 \pm 0.35$ & $2.29 \pm 0.25$ & 0.0045 \\
\hline Valine & $9.65 \pm 0.46$ & $9.51 \pm 0.46$ & 0.0009 \\
\hline \multicolumn{4}{|l|}{ Lipids } \\
\hline Fatty acids with $\alpha-\mathrm{CH} 2$ & $10.6 \pm 0.89$ & $10.8 \pm 0.78$ & 0.0057 \\
\hline Fatty acids with (-CH2-)n & $51.2 \pm 6.59$ & $51.3 \pm 5.51$ & 0.81 \\
\hline $\begin{array}{l}\text { Fatty acids with }=\mathrm{CH}-\mathrm{CH} 2- \\
\mathrm{CH} 2=+ \text { citrate }\end{array}$ & $16.7 \pm 1.89$ & $17.0 \pm 1.34$ & 0.019 \\
\hline Fatty acids with $-\mathrm{CH} 3$ & $64.8 \pm 6.83$ & $64.2 \pm 4.52$ & 0.20 \\
\hline $\begin{array}{l}\text { Fatty acids with }=\mathrm{CH}- \\
\mathrm{CH} 2-\mathrm{CH} 2-\end{array}$ & $36.1 \pm 1.23$ & $36.0 \pm 1.09$ & 0.52 \\
\hline Fatty acids with $-\mathrm{CH}=\mathrm{CH}$ & $11.1 \pm 2.62$ & $11.8 \pm 2.42$ & 0.0016 \\
\hline HDL apolipoproteins & $46.0 \pm 6.96$ & $44.6 \pm 5.65$ & 0.0099 \\
\hline Cholesterol & $22.6 \pm 4.88$ & $21.9 \pm 2.73$ & 0.012 \\
\hline Valerate & $35.7 \pm 7.91$ & $38.5 \pm 8.03$ & $<0.0001$ \\
\hline Fatty acids with $\beta-\mathrm{CH} 2$ & $39.7 \pm 2.00$ & $39.7 \pm 1.22$ & 0.75 \\
\hline 3-Hydroxybutyrate & $18.4 \pm 2.30$ & $18.5 \pm 3.59$ & 0.82 \\
\hline \multicolumn{4}{|l|}{ Carbohydrates } \\
\hline$\alpha$-Glucose & $2.27 \pm 0.42$ & $2.39 \pm 0.56$ & 0.010 \\
\hline Glucose+taurine & $9.31 \pm 1.21$ & $9.26 \pm 1.19$ & 0.61 \\
\hline Glucose & $20.2 \pm 2.18$ & $20.6 \pm 2.67$ & 0.048 \\
\hline Glycoprotein & $15.5 \pm 0.79$ & $15.9 \pm 1.09$ & 0.0003 \\
\hline \multicolumn{4}{|l|}{ Organic acids } \\
\hline Acetate & $5.36 \pm 0.31$ & $5.29 \pm 0.42$ & 0.037 \\
\hline 4-Hydroxybutyrate & $16.0 \pm 1.29$ & $15.6 \pm 0.91$ & $<0.0001$ \\
\hline Lactate & $13.7 \pm 2.49$ & $14.7 \pm 2.47$ & $<0.0001$ \\
\hline 2-0xobutyrate & $4.67 \pm 0.62$ & $4.83 \pm 0.49$ & 0.0006 \\
\hline \multicolumn{4}{|l|}{ Other metabolites } \\
\hline Creatinine & $2.84 \pm 0.21$ & $2.83 \pm 0.16$ & 0.26 \\
\hline Choline & $3.31 \pm 1.09$ & $3.21 \pm 0.38$ & 0.055 \\
\hline
\end{tabular}

Continued
Table 4. Continued

\begin{tabular}{|c|c|c|c|}
\hline Metabolic Biomarker & $\begin{array}{l}\text { Normal } \\
(n=538)\end{array}$ & $\begin{array}{l}\text { Abnormal } \\
(n=173)\end{array}$ & $P$ Value \\
\hline Ethanolamine & $0.81 \pm 0.15$ & $0.83 \pm 0.13$ & 0.89 \\
\hline Trimethylamine & $0.55 \pm 0.13$ & $0.54 \pm 0.12$ & 0.45 \\
\hline Glycerol & $1.91 \pm 0.38$ & $1.91 \pm 0.16$ & 0.72 \\
\hline Ethanol & $4.55 \pm 0.52$ & $4.52 \pm 0.38$ & 0.50 \\
\hline $\begin{array}{l}\text { Creatine+creatine- } \\
\text { phosphate }\end{array}$ & $1.49 \pm 0.14$ & $1.47 \pm 0.12$ & 0.027 \\
\hline Phosphocholine & $6.50 \pm 1.09$ & $6.17 \pm 1.05$ & 0.0006 \\
\hline Glucose +2 -aminobutyrate & $6.16 \pm 0.57$ & $6.29 \pm 0.73$ & 0.044 \\
\hline Glucose+glutamine & $6.08 \pm 0.56$ & $6.16 \pm 0.53$ & 0.11 \\
\hline $\begin{array}{l}\text { Glucose+2- } \\
\text { phosphoglycerate }\end{array}$ & $1.42 \pm 0.13$ & $1.43 \pm 0.13$ & 0.31 \\
\hline Unknown molecule & $3.56 \pm 0.31$ & $3.55 \pm 0.29$ & 0.55 \\
\hline
\end{tabular}

Diastolic dysfunction includes an abnormally low age-specific transmitral E/A ratio without increased LV filling pressures $\left(E / e^{\prime} \leq 8.5\right)$ or an elevated $L V$ filling pressure $\left(E / e^{\prime}\right.$ $>8.5$ ) with normal or low age-specific E/A (see references 4 and 5). $P$ values denote the significance of the differences between groups. LV indicates left ventricular.

MA) using in-house scripts for data analysis. Signals belonging to selected metabolites were integrated and quantified, using semiautomated in-house MATLAB peak-fitting routines. These fitting routines were based on Levenburg-Marquard optimization procedures. The target function for the optimization included experimental spectra measured for standard solutions of selected metabolites with complex multiplet patterns and theoretically generated Lorentzian-shape signals for those metabolites with simpler spectral patterns.

\section{Other Measurements}

Blood pressure was the average of 5 consecutive auscultatory readings obtained according to European guidelines with a standard mercury sphygmomanometer with the participant resting in the seated position for at least 5 minutes. ${ }^{19}$ Hypertension was a blood pressure of at least $140 \mathrm{~mm} \mathrm{Hg}$ systolic or $90 \mathrm{~mm} \mathrm{Hg}$ diastolic or use of antihypertensive drugs. Body mass index (BMI) was weight in kilograms divided by height in meters squared. Venous blood samples were drawn after at least 8 hours of fasting for measurement of plasma glucose and serum total and high-density lipoprotein (HDL) cholesterol, creatinine, $\gamma$-glutamyltransferase (biomarker of alcohol intake), and insulin. The homeostatic model assessment (HOMA) index was computed from glucose and insulin. ${ }^{20}$ Glomerular filtration rate (GRF) was derived by the Chronic Kidney Disease Epidemiology Collaboration equation. ${ }^{21}$ Diabetes mellitus was a self-reported diagnosis, a fasting glucose level of at least $7 \mathrm{mmol} / \mathrm{L}$, or use of antidiabetic agents. ${ }^{22}$ In 649 participants, N-terminal of the prohormone BNP (NT-proBNP) was measured in plasma by a 
competitive enzyme immunoassay (EIA) for research use (Biomedica Gruppe, Vienna, Austria).

\section{Statistical Analysis}

For database management and statistical analysis, we used the SAS system (version 9.3; SAS Institute Inc., Cary, NC). Means were compared using the large-sample $z$-test or ANOVA and proportions by Fisher's exact test. We normalized the distributions of $\gamma$-glutamyltransferase, insulin, and NT-proBNP by a logarithmic transformation. Our statistical methods also included multivariable linear regression with, as dependent variables, the echocardiographic indexes of diastolic LV function. We identified variables to be retained in the analyses by a step-wise regression procedure with $P$ value for variables to enter and stay in the models set at 0.15 . Statistical significance was a 2-sided $P$ level of 0.05 . Where appropriate, we applied Bonferroni correction for multiple testing by multiplying $P$ values by 44 (the number of metabolites tested). The annotation $P$ and $P_{\mathrm{B}}$ refer to significance levels unadjusted and adjusted for multiple testing.

We constructed a $-\log 10$ probability plot for the multivariable-adjusted associations of the diastolic LV function indexes with the metabolites. In the next step of our analyses, we dichotomized the study population in 538 participants with normal LV function and in 173 with subclinical diastolic LV dysfunction ${ }^{4,5}$ and used a binary dummy variable indicating membership to these 2 groups as a dependent variable in a partial least squares discriminant analysis (PLS-DA) to identify a set of independent latent factors (LFs) that were linear combinations of the metabolites and that maximized the covariance between the metabolites and LV diastolic dysfunction. We retained the smallest number of latent factors for which the predicted residual sums of squares (PRESS; calculated using leave-one-out cross-validation) did not differ significantly $(P>0.10)$ from the model with the minimum PRESS value as assessed by the van der Voet $\mathrm{T}^{2}$ statistic. The importance of each metabolite in the construction of the PLS factors was assessed from the Variable Importance in Projection (VIP) scores of Wold.

Finally, we evaluated the capability of the LFs to discriminate between participants with and without diastolic LV dysfunction by constructing the receiver operating characteristic (ROC) curve and by calculating the area under the ROC curve (AUC). The $95 \% \mathrm{Cl}$ of the AUC was calculated by the DeLong method. ${ }^{23}$ The discriminative capability of the latent factors on top of NT-proBNP was assessed by comparing the AUCs from a basic model including NT-proBNP and an extended model including NT-proBNP plus the LFs. We tested the statistical significance of the change in AUC attributable to adding the LFs to NT-proBNP by the Delong test for paired ROC curves. ${ }^{23}$

\section{Results}

\section{Characteristics of Participants}

Of 711 participants, 361 (50.8\%) were women. All subjects were white Europeans. Mean values (SD) in all participants

Table 5. Covariates Selected by Step-wise Regression

\begin{tabular}{|c|c|c|c|c|c|c|c|}
\hline Variables & E Peak & A Peak & $\mathrm{E} / \mathrm{A}$ & $e^{\prime}$ & $a^{\prime}$ & $e^{\prime} / a^{\prime}$ & $E / e^{\prime}$ \\
\hline$R^{2}$ & 0.27 & 0.68 & 0.66 & 0.75 & 0.50 & 0.72 & 0.46 \\
\hline Female sex $(0,1)$ & $9.284^{\S}$ & $5.944^{\S}$ & - & $-0.354^{\dagger}$ & $-0.950^{\S}$ & $0.078^{*}$ & $1.109^{\S}$ \\
\hline Body mass index $\left(+4.3 \mathrm{~kg} / \mathrm{m}^{2}\right)$ & - & $3.188^{\S}$ & $-0.077^{\S}$ & $-0.630^{\S}$ & $0.385^{\S}$ & $-0.138^{\S}$ & $0.291^{\S}$ \\
\hline Mean arterial pressure $(+10.4 \mathrm{~mm} \mathrm{Hg})$ & - & $1.943^{\S}$ & $-0.024^{\dagger}$ & $-0.308^{\S}$ & - & $-0.035^{\dagger}$ & $0.320^{\S}$ \\
\hline Total cholesterol $(+0.95 \mathrm{mmol} / \mathrm{L})$ & $-1.127^{\dagger}$ & - & -0.029 & $-0.200^{*}$ & $0.173^{\ddagger}$ & $-0.063^{\S}$ & - \\
\hline Log $\gamma$-glutamyltransferase $(\times 2)$ & - & $-5.843^{\star}$ & - & $-2.571^{\S}$ & $0.938^{*}$ & $-0.290^{\dagger}$ & - \\
\hline Fasting plasma glucose $(+0.77 \mathrm{mmol} / \mathrm{L})$ & $0.835^{\star}$ & - & - & $0.115^{\star}$ & - & - & $0.109^{*}$ \\
\hline LVMI $\left(+21.9 \mathrm{~g} / \mathrm{m}^{2}\right)$ & - & - & - & $-0.332^{\S}$ & $-0.237^{\star}$ & - & $0.360^{\S}$ \\
\hline
\end{tabular}

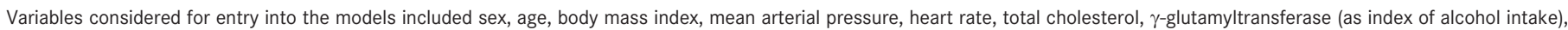

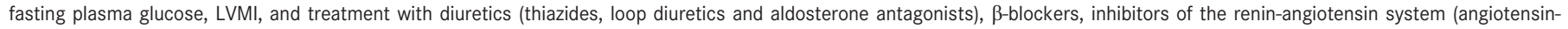

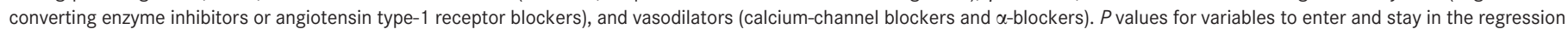
models were set at 0.15 . LVMI left ventricular mass index; RAAS, renin-angiotensin-aldosterone system.

Significance of the association: ${ }^{\star} 0.05<P \leq 0.15 ;{ }^{\dagger} P \leq 0.05 ;{ }^{\star} P \leq 0.01 ;{ }^{\S} P \leq 0.001$. 


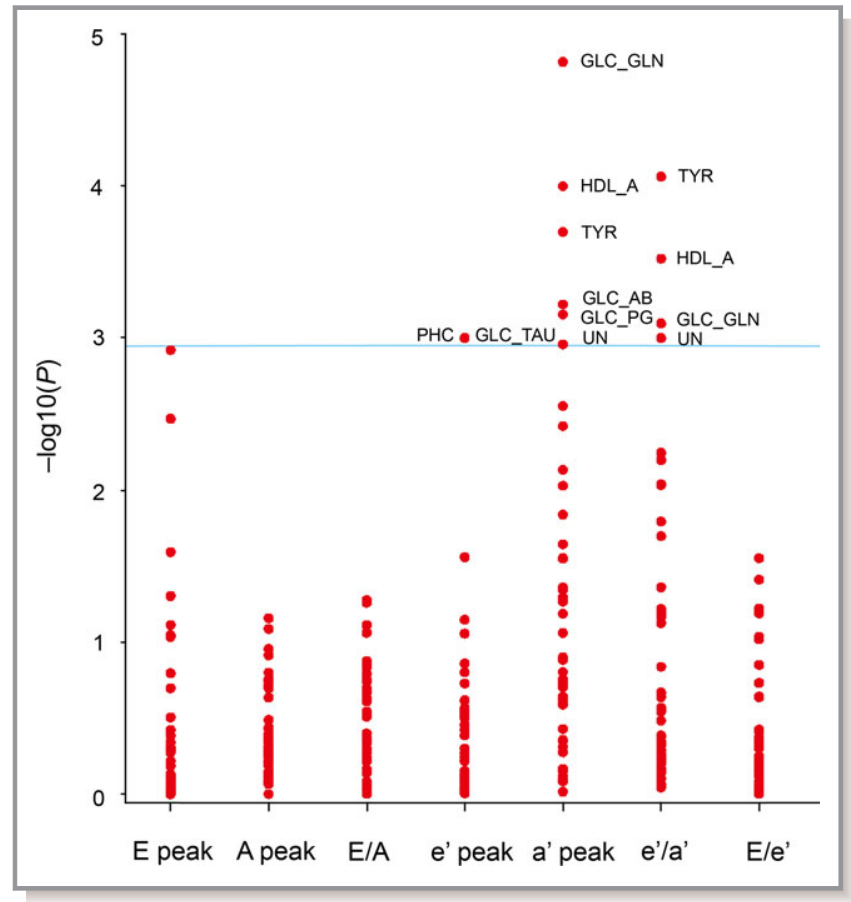

Figure 1. - Log $10(P)$ probability plot of the multivariable-adjusted associations of various indexes of diastolic left ventricular dysfunction (see Table 6) with the metabolic biomarkers. TYR, HDL_A, GLC_TAU, PHC, GLC_AB, GLC_GLN, GLC_PG, and UN, respectively, indicate tyrosine, high-density lipoprotein apolipoproteins, glucose+taurine, phosphocholine, glucose+2-aminobutyrate, glucose+glutamine, glucose+2-phosphoglycerate, and unknown molecule. The adjustment accounted for sex, age, body mass index, mean arterial pressure, heart rate, total cholesterol, $\gamma$-glutamyltransferase, fasting plasma glucose, treatment with diuretics, $\beta$-blockers, and inhibitors of the renin-angiotensin system. The horizontal line denotes the significance level with Bonferroni correction applied.

combined were 50.8 (15.4) years for age, 129.0 (17.0) and 79.7 (9.3) $\mathrm{mm} \mathrm{Hg}$ for systolic and diastolic blood pressure, 26.5 (4.3) $\mathrm{kg} / \mathrm{m}^{2}$ for BMI, and $5.24(0.95) \mathrm{mmol} / \mathrm{L}$ for total cholesterol. Of all participants, 287 (40.4\%) had hypertension, of whom 177 (61.7\%) were on antihypertensive drug treatment, and 9 (1.3\%) had diabetes. The prevalence of diastolic LV dysfunction amounted to $173(24.3 \%)$, because of impaired relaxation in $70(40.5 \%)$ or an elevated filling pressure in the presence of a normal (79 [45.7\%]) or low (24 [13.9\%]) age-specific E/A ratio.

\section{Associations of Diastolic LV Function With Metabolites}

\section{Unadjusted analyses}

Comparing with participants with normal function (Table 1), age, BMI, central obesity, blood pressure, heart rate, serum creatinine, $\gamma$-glutamyltransferase and insulin, plasma glucose, total-to-HDL cholesterol ratio, and NT-proBNP all increased $(P \leq 0.005)$, whereas estimated GFR (eGFR) decreased
Table 6. Multivariable-Adjusted Associations of Tissue Doppler indexes With Metabolites

\begin{tabular}{|c|c|c|}
\hline Metabolic Markers (SD) & Estimate $(95 \% \mathrm{Cl})$ & $P_{B}$ Value \\
\hline \multicolumn{3}{|l|}{ Tyrosine $(0.327)$} \\
\hline a' peak & $-0.225(-0.419,-0.030)$ & 0.009 \\
\hline$e^{\prime} / a^{\prime}$ & $0.054(0.010,0.099)$ & 0.004 \\
\hline \multicolumn{3}{|c|}{ HDL apolipoproteins (6.689) } \\
\hline a' peak & $-0.229(-0.425,-0.034)$ & 0.004 \\
\hline e'/a' & $0.050(0.005,0.095)$ & 0.013 \\
\hline \multicolumn{3}{|c|}{ Glucose+taurine (1.209) } \\
\hline e' peak & $0.250(0.005,0.496)$ & 0.044 \\
\hline \multicolumn{3}{|l|}{ Phosphocholine (1.091) } \\
\hline e' peak & $0.255(0.003,0.507)$ & 0.044 \\
\hline \multicolumn{3}{|c|}{ Glucose+2-aminobutyrate $(0.616)$} \\
\hline a' peak & $-0.261(-0.509,-0.014)$ & 0.026 \\
\hline \multicolumn{3}{|c|}{ Glucose+glutamine $(0.552)$} \\
\hline a' peak & $-0.277(-0.483,-0.070)$ & 0.0007 \\
\hline e'/a' & $0.049(0.001,0.097)$ & 0.035 \\
\hline \multicolumn{3}{|c|}{ Glucose+2-phosphoglycerate $(0.131)$} \\
\hline a' peak & $-0.209(-0.407,-0.010)$ & 0.031 \\
\hline \multicolumn{3}{|c|}{ Unknown molecule (0.307) } \\
\hline a' peak & $-0.203(-0.404,-0.002)$ & 0.048 \\
\hline$e^{\prime} / a^{\prime}$ & $0.047(0.001,0.093)$ & 0.044 \\
\hline
\end{tabular}

All estimates were adjusted for sex, age, body mass index, mean arterial pressure, heart rate, total cholesterol, $\gamma$-glutamyltransferase, plasma glucose, LV mass index, and treatment with diuretics, $\beta$-blockers, and inhibitors of the renin-angiotensin system. Estimates express the change in the dependent variable for a 1-SD increase in circulating metabolites. $P$ values and $95 \% \mathrm{Cls}$ account for testing 44 metabolites according to the Bonferroni approach. HDL indicates high-density lipoprotein; LV, left ventricular.

$(P<0.0001)$, in participants with diastolic LV dysfunction. Table 2 shows that LA volume, LA volume index, LV mass, LV mass index (LVMI), deceleration time, isovolumetric relaxation time, $\mathrm{A}$ and a' peak velocities, and $\mathrm{E} / \mathrm{e}$ ' ratio increased $(P<0.0001)$ in participants with diastolic LV dysfunction, whereas the opposite was the case $(P<0.0001)$ for $E$ and $e^{\prime}$ peak velocities and the E/A and e'/a' ratios. Table 3 lists the circulating metabolites subdivided into amino acids, lipids, carbohydrates, organic acids, and other molecules. Table 4 shows that of 44 non-overlapping metabolites, 24 showed significant differences between 2 groups. Generally, amino acids were lower in diastolic LV dysfunction group (8 of 8 significant associations), whereas fatty acids were higher ( 4 of 6 significant associations).

\section{Multivariable-adjusted regression}

Variables considered for entry and retained for multivariable adjustment of the indexes of diastolic LV function are listed in 
Table 7. Factor Loadings of the Metabolic Biomarkers in Analyses Contrasting Normal With Diastolic LV Dysfunction

\begin{tabular}{|c|c|c|c|}
\hline Metabolic Biomarker & LF1 & LF2 & LF3 \\
\hline \multicolumn{4}{|l|}{ Amino acids } \\
\hline 2-Aminobutyrate & -0.25 & 0.13 & -0.10 \\
\hline 4-Aminobutyrate & -0.23 & 0.16 & -0.14 \\
\hline Alanine & -0.26 & 0.04 & -0.03 \\
\hline Aspartate & -0.02 & 0.15 & -0.27 \\
\hline Glutamate & -0.13 & 0.15 & -0.26 \\
\hline Glycine & -0.07 & 0.23 & -0.01 \\
\hline Glutamine & -0.13 & 0.16 & -0.27 \\
\hline Isoleucine & -0.11 & -0.11 & 0.12 \\
\hline Leucine & -0.24 & 0.13 & -0.12 \\
\hline Phenylalanine & -0.01 & 0.16 & -0.26 \\
\hline Threonine & -0.08 & 0.26 & 0.02 \\
\hline Tyrosine & -0.15 & 0.06 & -0.05 \\
\hline Valine & -0.18 & -0.13 & 0.13 \\
\hline \multicolumn{4}{|l|}{ Lipids } \\
\hline Fatty acid with $\alpha-\mathrm{CH} 2$ & 0.21 & 0.01 & -0.21 \\
\hline Fatty acid with (-CH2-)n & 0.12 & -0.21 & 0.14 \\
\hline Fatty acid with $=\mathrm{CH}-\mathrm{CH} 2-\mathrm{CH} 2=+$ citrate & 0.01 & 0.14 & -0.23 \\
\hline Fatty acid with $-\mathrm{CH} 3$ & -0.03 & -0.19 & 0.24 \\
\hline Fatty acid with $=\mathrm{CH}-\mathrm{CH} 2-\mathrm{CH} 2-$ & 0.05 & -0.18 & 0.10 \\
\hline Fatty acid with $-\mathrm{CH}=\mathrm{CH}$ & 0.24 & -0.07 & -0.07 \\
\hline HDL apolipoproteins & -0.15 & 0.08 & -0.08 \\
\hline Cholesterol & -0.08 & -0.12 & 0.27 \\
\hline Valerate & 0.31 & -0.10 & -0.05 \\
\hline Fatty acid with $\beta$-CH2 & 0.05 & -0.02 & -0.22 \\
\hline 3-Hydroxybutyrate & -0.01 & -0.13 & 0.25 \\
\hline \multicolumn{4}{|l|}{ Carbohydrates } \\
\hline$\alpha$-glucose & 0.11 & 0.07 & 0.05 \\
\hline Glucose+taurine & -0.06 & 0.05 & -0.07 \\
\hline Glucose & -0.04 & 0.26 & -0.02 \\
\hline Glycoprotein & 0.19 & 0.09 & -0.04 \\
\hline \multicolumn{4}{|l|}{ Organic acids } \\
\hline Acetate & -0.25 & 0.08 & 0.06 \\
\hline 4-Hydroxybutyrate & -0.25 & 0.10 & -0.13 \\
\hline Lactate & 0.28 & -0.03 & -0.12 \\
\hline 2-0xobutyrate & 0.13 & 0.08 & -0.23 \\
\hline \multicolumn{4}{|l|}{ Other metabolites } \\
\hline Creatinine & 0.01 & 0.15 & -0.24 \\
\hline Choline & -0.06 & 0.03 & 0.04 \\
\hline Ethanolamine & -0.10 & 0.16 & -0.08 \\
\hline Trimethylamine & -0.01 & 0.14 & -0.18 \\
\hline
\end{tabular}

Continued
Table 7. Continued

\begin{tabular}{|l|l|l|l|}
\hline Metabolic Biomarker & LF1 & LF2 & LF3 \\
\hline Glycerol & -0.09 & 0.16 & -0.04 \\
\hline Ethanol & -0.14 & 0.14 & 0.12 \\
\hline Creatine+creatine-phosphate & -0.15 & 0.21 & -0.14 \\
\hline Phosphocholine & -0.14 & -0.08 & -0.01 \\
\hline Glucose+2-aminobutyrate & -0.03 & 0.23 & 0.12 \\
\hline Glucose+glutamine & -0.10 & 0.28 & 0.02 \\
\hline Glucose+2-phosphoglycerate & -0.13 & 0.24 & 0.09 \\
\hline Unknown molecule & -0.14 & 0.22 & 0.06 \\
\hline
\end{tabular}

The study population was dichotomized in 538 participants with normal LV function and 173 with subclinical diastolic LV dysfunction. ${ }^{4,5}$ LF1, LF2, and LF3 refer to the first, second, and third latent factors derived by partial least square discriminant analysis of 44 metabolites. LV indicates left ventricular.

Table 5. We adjusted the associations of the indexes of diastolic LV function for sex, age, BMI, mean arterial pressure, heart rate, total cholesterol, $\gamma$-glutamyltransferase, plasma glucose, LVMI and treatment with diuretics, $\beta$-blockers, and inhibitors of the renin-angiotensin system and applied Bonferroni correction of the significance levels. Under these conditions, the transmitral blood flow Doppler indexes were not correlated with any circulating metabolite. There was a positive correlation of e' peak velocity with glucose+taurine and phosphocholine (Figure 1; $P_{\mathrm{B}}=0.044$ for both). Significance was also preserved (Figure 1) for the negative correlations of a' peak velocity with tyrosine, HDL apolipoproteins, glucose+2-aminobutyrate, glucose+glutamine, glucose+2phosphoglycerate, and an unknown molecule $\left(P_{\mathrm{B}} \leq 0.048\right)$ and the positive correlations of $e^{\prime} / a^{\prime}$ with tyrosine, HDL apolipoproteins, glucose+glutamine, and an unknown molecule $\left(P_{\mathrm{B}} \leq 0.044\right)$. Table 6 lists quantitative estimates for the association sizes expressing the differences in the diastolic LV function indexes per 1-SD increment in the circulating metabolites with $95 \% \mathrm{Cls}$ rescaled to the Bonferroni significance level. The results reported in Figure 1 and Table 6 remained consistent, if models were additionally adjusted for insulin or if glucose was replaced by the HOMA index. ${ }^{20}$ However, additional adjustment for HDL cholesterol or replacing total cholesterol by the total-to-HDL cholesterol ratio removed the significance of the associations of e' peak velocity with glucose+taurine and phosphocholine.

\section{Partial Least Square Discriminant Analysis}

We dichotomized the study population in 538 participants with normal LV function and in 173 with subclinical diastolic LV dysfunction. ${ }^{4,5}$ The PLS-DA procedure identified 3 latent factors accounting for $19.5 \%, 21.3 \%$, and $13.6 \%$ of the 
Table 8. VIP Scores in Analyses Contrasting Normal With Diastolic LV Dysfunction

\begin{tabular}{|l|l|}
\hline Metabolomic Biomarker & VIP Score \\
\hline Lactate & 1.433 \\
\hline 4-Aminobutyrate & 1.411 \\
\hline Glycoprotein & 1.403 \\
\hline Valerate & 1.398 \\
\hline Creatinine & 1.271 \\
\hline 4-Hydroxybutyrate & 1.269 \\
\hline Alanine & 1.267 \\
\hline Valine & 1.247 \\
\hline Glucose+glutamine & 1.201 \\
\hline Glucose & 1.187 \\
\hline Glucose+2-aminobutyrate & 1.185 \\
\hline Glucose+2-phosphoglycerate & 1.172 \\
\hline Acetate & 1.143 \\
\hline Phosphocholine & 1.142 \\
\hline Threonine & 1.126 \\
\hline 2-Aminobutyrate & 1.112 \\
\hline Leucine & 1.112 \\
\hline Fatty acid with -CH=CH & 1.106 \\
\hline 2-0xobutyrate & 1.027 \\
\hline Fatty acid with $\alpha-C H 2$ & 1.024 \\
\hline Creatine+creatine-phosphate & 1.024 \\
\hline$\alpha-G l u c o s e$ & 1.007 \\
\hline & \\
\hline & \\
\hline
\end{tabular}

Variable Importance in Projection (VIP) scores estimate the importance of each variable in the projection used in a partial least square (PLS) model and is often used for variable selection. A variable with a VIP score greater than 1 can be considered important in a given model. LV indicates left ventricular.

variance in the metabolites and $54.4 \%$ in total. Table 7 presents the factor loadings of the circulating metabolites on LF1, LF2, and LF3. As listed in Table 8, metabolites with a VIP score greater than 1 included phosphocholine (1.142), glucose+2-aminobutyrate (1.185), glucose+glutamine (1.201), and glucose+2-phosphoglycerate (1.172), but not tyrosine (0.808), HDL apolipoproteins (0.806), glucose+taurine (0.265), and unknown molecule (0.733). Figure 2 shows the V-plot for the PLS-DA-derived VIP scores versus the centered and rescaled correlation coefficients. The dependent variable in this analysis was diastolic LV dysfunction. The metabolites associated with normal diastolic LV function (left side of the V-plot in Figure 2) included, among others, glucose+glutamine, glucose+2-aminobutyrate, and glucose+2-phosphoglycerate. Metabolites siding with abnormal diastolic LV function (right side of the V-plot in Figure 2) encompassed 4-aminobutyrate, 4-hydroxybutyrate, creatinine, and phosphocholine.

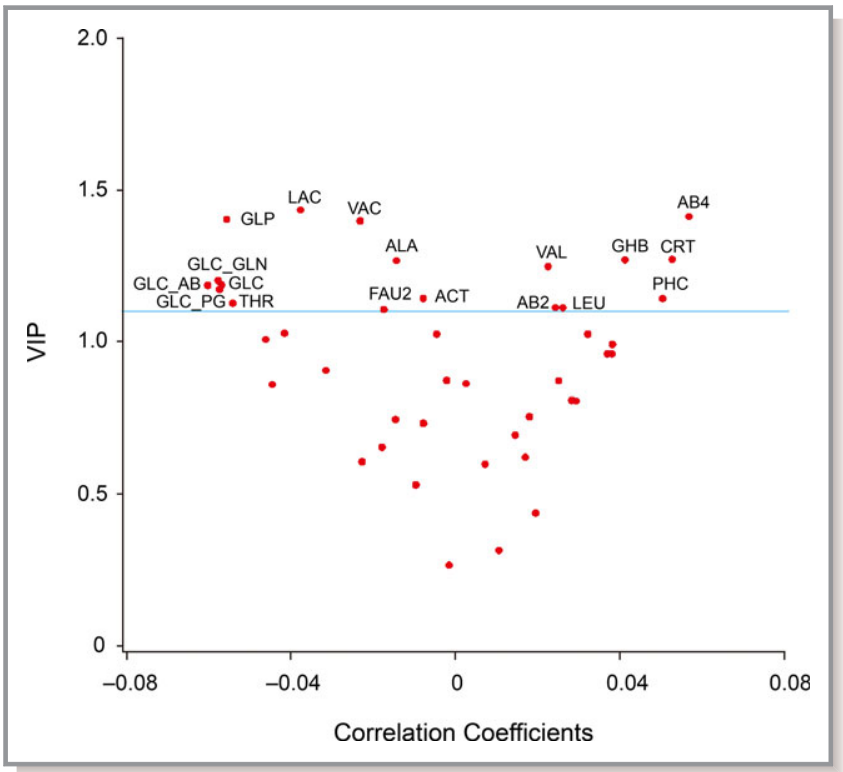

Figure 2. After dichotomizing the study population in 538 participants with normal LV function and 173 with subclinical diastolic LV dysfunction, V-plots were generated for the PLS-DAderived VIP scores versus the centered and rescaled correlation coefficients. Spots indicating metabolites with a VIP score higher than 1.1 were labeled. Spots associated with normal diastolic LV function (left), ordered by descending VIP score include lactate $(\mathrm{LAC})$, glycoprotein (GLP), valerate (VAC), alanine (ALA), glucose+glutamine (GLC-GLN), glucose (GLC), glucose+2-aminobutyrate (GLC-AB), glucose+2-phosphoglycerate (GLC-PG), acetate (ACT), threonine (THR), and fatty acid with $-\mathrm{CH}=\mathrm{CH}$ (FAU2). Spots associated with diastolic LV dysfunction (right), ordered by ascending VIP score, include leucine (LEU), 2-aminobutyrate $(A B 2)$, phosphocholine (PHC), valine (VAL), 4-hydroxybutyrate (GHB), creatinine (CRT), and 4-aminobutyrate (AB4). LV indicates left ventricular; PLS-DA, partial least square discriminant analysis; VIP, Variable Importance in Projection.

\section{Receiver Operating Curves}

Measurement of NT-proBNP in plasma is currently the standard in diagnosing LV dysfunction and monitoring its treatment. Figure 3 shows that combining the 3 latent factors identified by PLS-DA to NT-proBNP increased $(P<0.0001)$ the AUC from $0.64(95 \% \mathrm{Cl}, 0.58-0.68)$ to $0.73(0.68-0.78)$.

\section{Discussion}

In the current study, we applied 2 different methods to investigate association of diastolic LV function with circulating metabolites. In multivariable-adjusted regression models with Bonferroni correction of significance levels applied, a' was inversely and e'/a' was positively correlated with circulating tyrosine, HDL apolipoproteins, glucose+glutamine, and an unknown molecule, whereas a' was also inversely associated 


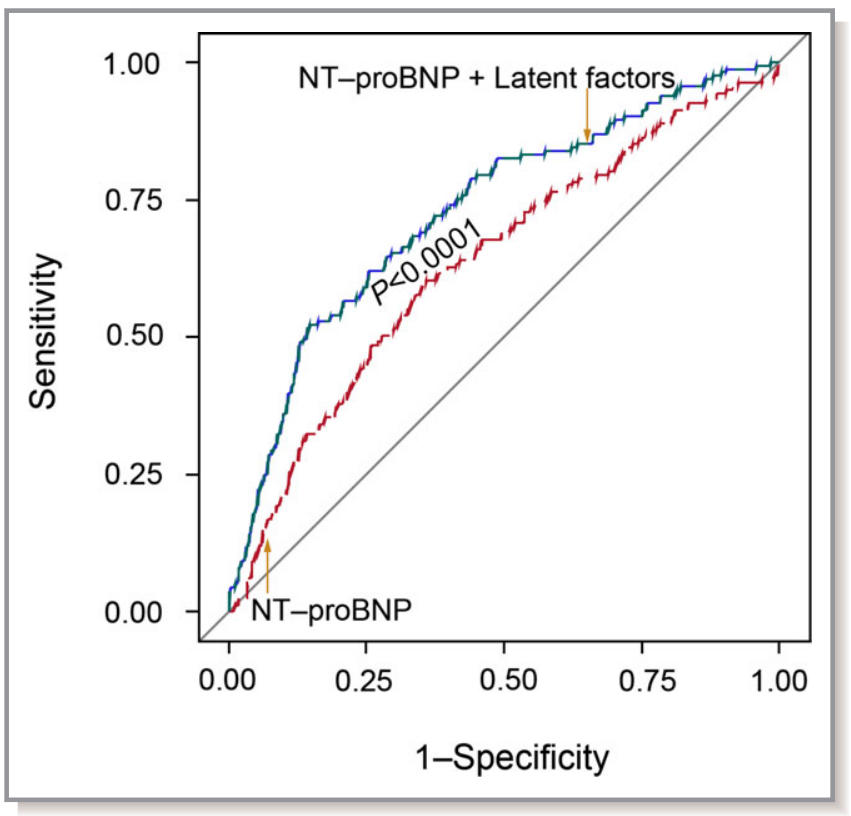

Figure 3. Receiver operating characteristic (ROC) curves for discriminating between normal and abnormal diastolic LV function using NT-proBNP (red line) or NT-proBNP plus 3 latent factors identified by PLS-DA (green line). Combining the 3 latent factors with NT-proBNP increased $(P<0.0001)$ the AUC from 0.64 to 0.73 . AUC indicates area under the curve; LV, left ventricular; NT-proBNP, $\mathrm{N}$-terminal of the prohormone brain natriuretic peptide; PLS-DA, partial least square discriminant analysis.

with glucose+2-aminobutyrate and glucose +2 -phosphoglycerate (Table 6). In PLS-DA, metabolites associated with normal diastolic LV function included glucose+glutamine, glucose+2aminobutyrate, and glucose +2 -phosphoglycerate, whereas those siding with abnormal function encompassed 4-aminobutyrate, 4-hydroxybutyrate, creatinine, and phosphocholine (Figure 2).

In multivariable-adjusted regression analyses (Table 6), the early diastolic e' peak was positively associated with glucose+taurine and with phosphocholine. The late diastolic a' peak velocity, either as single measurement or as denominator in the e' /a' ratio, was the other trait associated with the circulating metabolites. Impaired relaxation, as reflected by the early diastolic e' peak velocity, is usually the first step in the progression toward diastolic LV dysfunction, but it is also part of the normal aging process. ${ }^{4,5}$ Stiffening of the LV occurs later and requires a greater contribution of the atrial contraction to late diastolic LV filling. This might explain why, in multiple linear regression, fewer metabolites were associated with e' than a'. This interpretation is also in keeping with the observation that in our study population, in contrast to hospitalized patients with end-stage $\mathrm{HF}$, only 11 participants, all with high LV filling pressure, had an e'/a' ratio higher than unity.

Extruding calcium from cardiomyocytes during early diastole to facilitate cardiac relaxation and diastolic filling requires high amounts of energy. ${ }^{24}$ Higher availability of energy substrate might improve LV relaxation and reduce the atrial contribution to LV filling. Glucose+2-phosphoglycerate and glucose+glutamine, 2 metabolic markers involved in the generation of energy, were associated with lower a' peak velocity (Figure 1 and Table 6) and better diastolic LV function (Figure 2). As shown in Figure 4, 2-phosphoglycerate is an intermediate metabolite in the cytosolic anaerobic glycolysis pathway, which converts 1 glucose molecule into 2 pyruvate moieties, with a net production of ATP. ${ }^{25}$ This pathway also generates reduced $\mathrm{NADH}$. Transferred to mitochondria, NADH links the citric acid cycle to oxidative phosphorylation, the major source of ATP. ${ }^{25}$ Oxygen being available, pyruvate produced by glycolysis is converted to acetyl-CoA (coenzyme A) and runs through the citric acid cycle, in which acetyl-CoA is completely oxidized generating ATP through oxidative phosphorylation. Glutamine is an alternative substrate (Figure 4) that, in the presence of glucose, can enter the citric acid cycle and generates energy by aerobic oxidation. ${ }^{26}$

The antioxidant, glutathione (GSH), is the main hepatic protection system against systemic oxidative stress. ${ }^{27}$ When hepatic availability of cysteine is limited and GSH is depleted, 2-aminobutyrate enters an alternative pathway driven by the same enzymes leading to the synthesis of ophthalmate. ${ }^{27,28}$ In our current study, a performant diastolic function, as exemplified by lower a' peak in the multivariable-adjusted regression analysis (Table 6) or a VIP-to-correlation-coefficient spot associated with normal diastolic LV function (left side of the V-plot in Figure 2) was associated with a higher glucose+2aminobutyrate signal. In multivariable-adjusted regression analyses (Table 6), the early diastolic e' peak correlated positively with glucose+taurine and the e'/a' ratio with $\mathrm{HDL}$ apolipoproteins, whereas the late diastolic a' peak was inversely related to tyrosine and HDL apolipoproteins. Protection against oxidative stress might underlie better diastolic LV function associated with these 2 markers reflecting amino acid (tyrosine) and lipid (HDL apolipoproteins) metabolism (Figure 4). Major sources of the amino acid, taurine, are hepatic biosynthesis from cysteine and dietary intake. ${ }^{29}$ Although the underlying mechanisms require further elucidation, several studies suggest that taurine inhibits the generation of ROS. ${ }^{29}$ Japanese studies, ${ }^{30}$ confirmed by other investigators, ${ }^{31,32}$ demonstrated that daily taurine administration to HF patients improved end-diastolic LV volume, ${ }^{31}$ key symptoms, ${ }^{30}$ and exercise capacity. ${ }^{32}$ Tyrosine, a product of phenylalanine degradation, is a precursor of dopamine and melanin. ${ }^{33}$ At the start of the pathway, phenylalanine upregulates expression and activity of guanosine- $5^{\prime}$-triphosphate cyclohydrolase I, which is the first and rate-controlling enzyme for synthesis of tetrahydrobiopterin, an essential cofactor for nitric oxide (NO) synthase and NO synthesis. ${ }^{34}$ Near the end of the tyrosine chain, dopamine and melanin reduce the 
synthesis of proinflammatory cytokines, including tumor necrosis factor alpha and interleukins 1b, 6, and 10, and induce production of anti-inflammatory mediators by leucocytes. ${ }^{34}$ Apolipoprotein (Apo) A1 and apoA2 are the major protein component of HDL lipoproteins and account for over two thirds of the protein content of HDL. Both HDL lipoproteins and HDL cholesterol possess anti-inflammatory and adhesive properties. ${ }^{35}$ Adjustment for HDL cholesterol or the total-to-HDL cholesterol ratio in the multivariable-adjusted regression analysis did not remove the associations of a' and e'/a' with HDL apolipoproteins.

Phospholipid bilayers, in which phosphatidylcholine is the main constituent, maintain the structure and functionality of cellular membranes. Phosphocholine is an intermediate metabolite in the cytidine diphosphocholine pathway that synthesizes phosphatidylcholine from choline (Figure 4), an essential nutrient primarily provided by the diet. Carnitine is a chemical analog of choline and mediates the transport of longchain fatty acids into the mitochondrial matrix for betaoxidation and has proven antioxidant and -inflammatory activity. In contrast, choline deficiency is associated with increased oxidative stress. ${ }^{36}$ Compared to controls, patients with diastolic HF have lower serum concentrations of phosphatidylcholines. ${ }^{37}$ L-carnitine is a nutritional supplement approved by regulatory agencies for use in cardiovascular and cardiac disease, including HF. ${ }^{38}$ In multiple linear regression, e' increased with higher circulating phosphocholine, but in the PLS-DA, that relied on various Doppler velocities other than e', the VIP-to-correlation-coefficient spot (right side of the V-plot in Figure 2) was associated with diastolic LV dysfunction. Adjustment for HDL-cholesterol or the total-to-HDL cholesterol ratio weakened the positive association of e' with phosphocholine in the multivariable-adjusted regression analysis, perhaps because HDL-lipoproteins are acceptors in the efflux of phospholipids and free cholesterol from peripheral cells. ${ }^{35}$

Strong points of our study are the availability of Doppler indexes of early subclinical diastolic LV dysfunction, application of 2 different approaches in the statistical analysis, and the population-based character of our research. The epidemiological angle enhances the relevance of our findings over and beyond that of case-control studies involving selected $\mathrm{HF}$ patients who represent the end stage of a long pathogenetic process confounded by multiple comorbidities and polymedication. ${ }^{11}$ However, our present study must also be interpreted within the context of its limitations. First, our findings originate from a cross-sectional analysis and therefore reflect a snapshot of a long-lasting process in each individual participant. Moreover, the pathogenetic drivers leading to

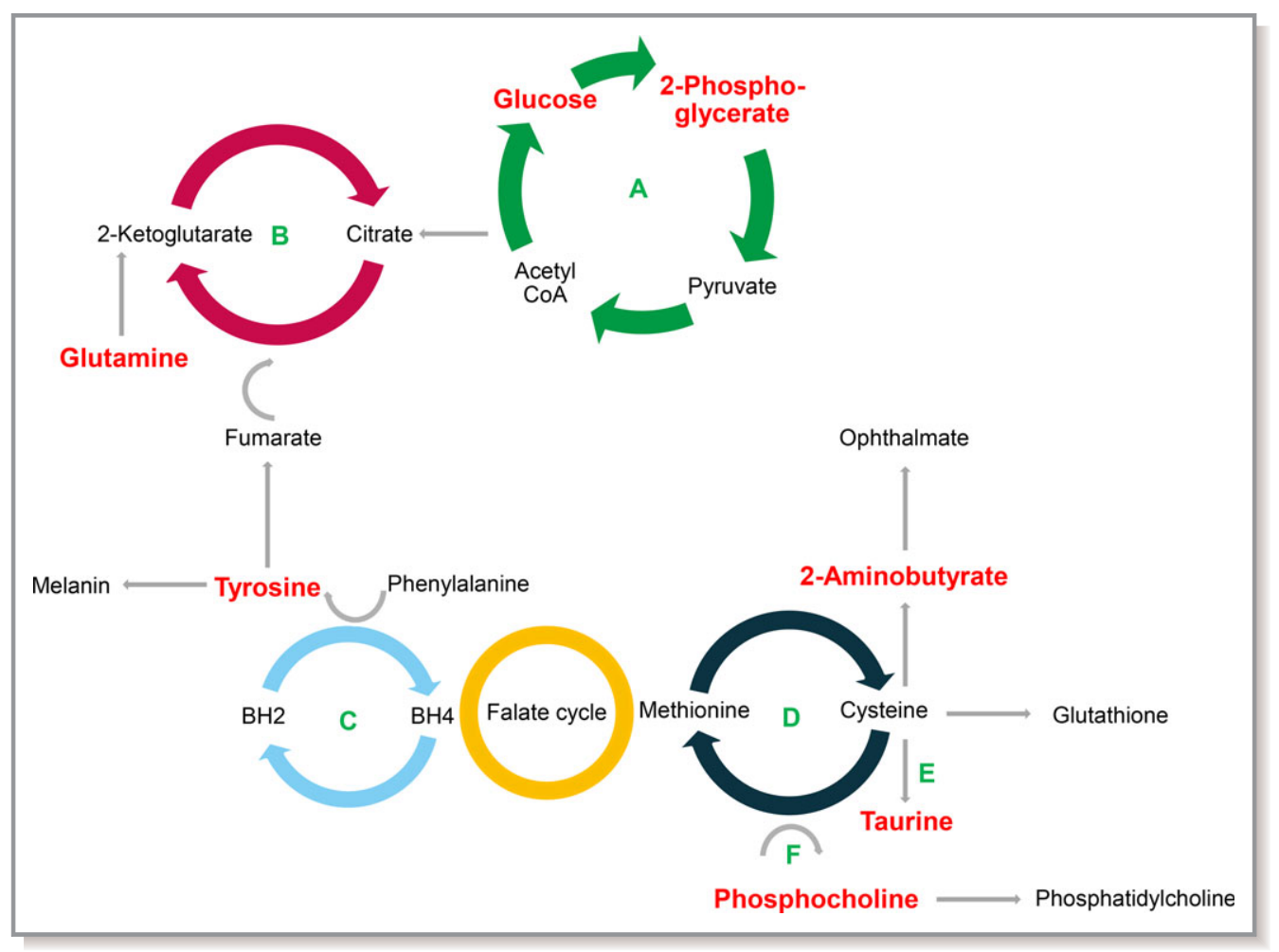

Figure 4. Simplified representation of metabolic pathways potentially involved in diastolic LV dysfunction. Metabolites significantly associated with diastolic LV function are in red color. Depicted cycles are (A) glycolysis; (B) citric acid (Krebs) cycle; (C) biopterin cycle; (D) 5-methylthioadenosine/ methionine cycle; (E) transsulfuration (taurine); and (F) methylation (phosphatdylcholine). $\mathrm{BH} 2$ and $\mathrm{BH} 4$ indicate dihydrobiopterin and tetrahydrobiopterin, respectively; CoA, coenzyme A; LV, left ventricular. 
diastolic LV dysfunction are multifaceted, each with different contributions among people at risk. Whether or not the metabolic markers can predict the course, over time, of diastolic LV dysfunction and associated cardiovascular complications remains to be proven in longitudinal studies. Second, keeping in mind the redundancy and bidirectionality in many metabolic pathways, ${ }^{25}$ studies like ours cannot determine whether levels of circulating metabolites vary because of changes in production or degradation or release into or clearance from the circulation, or because of a combination of these mechanisms. Third, epidemiological studies only demonstrate association. Our proposal of molecular pathways (Figure 4) linking diastolic LV dysfunction to the metabolic markers rests on our interpretation of the available literature. Fourth, our findings need replication in other cohorts and validation in molecular studies. Finally, NMR spectroscopy is fast and keeps samples separated from the instrument, but produces crowded spectra that cannot always be reliably deconvoluted to single metabolites. ${ }^{16}$

\section{Conclusions}

In this first population study of its kind, we identified a profile of circulating metabolites, indicative of energy substrate utilization and protection against oxidative stress, associated with diastolic LV function. In ROC curve analyses, adding the LFs to NT-proBNP increased the AUC. Given the current state of this newly emerging field of research, we believe that, in the near future, the principal application of metabolic markers might lie in the characterization of biochemical pathways leading to diastolic LV dysfunction rather than in diagnosing this condition. One line of research that we are currently pursuing in this respect is linking the metabolic profiles to markers of mitochondrial function. ${ }^{39}$ Deeper insights in the pathogenetic mechanisms causing diastolic HF will potentially identify new targets for prevention and treatment at a subclinical and still reversible stage.

\section{Acknowledgments}

Thibault Petit, MD, Yu-Mei Gu, MD, Judita Knez, MD, Nicholas Cauwenberghs, MSc, collected data at the field center of the Flemish Study on Environment, Genes and Health Outcomes (Eksel, Belgium) and Azusa Hara, PhD helped with database construction and end point validation at the Studies Coordinating Centre, Leuven, Belgium. The authors gratefully acknowledge the clerical assistance of $\mathrm{R}$. Wolfs and the technical support of L. Custers, M.J. Jehoul, D. Thijs and $\mathrm{H}$. Truyens in data collection.

\section{Sources of Funding}

The European Union (grants HEALTH-2011.2.4.2-2-EU-MASCARA, HEALTH-F7-305507 HOMAGE, and the European
Research Council Advanced Researcher Grant-2011-294713EPLORE) gave support to the Studies Coordinating Centre (Leuven, Belgium). The Fonds voor Wetenschappelijk Onderzoek Vlaanderen, Ministry of the Flemish Community (Brussels, Belgium; G.0881.13, G.0880.13, and $11 \mathrm{Z0916N)}$ also supported the FLEMENGHO study.

\section{Disclosures}

None.

\section{References}

1. Paulus WJ, Tschöpe C, Sanderson JE, Rusconi C, Flachskampf FA, Rademakers FE, Marino P, Smiseth OA, De Keulenaer G, Leite-Moreira AF, Borbély A, Edes I, Handoko ML, Heymans S, Pezzali N, Pieske B, Dickstein K, Fraser AG, Brutsaert DL. How to diagnose heart failure: a consensus statement on the diagnosis of heart failure with normal left ventricular ejection fraction by the Heart Failure and Echocardiography Associations of the European Society of Cardiology. Eur Heart J. 2007;28:2539-2550.

2. Go AS, Mozaffarian D, Roger VL, Benjamin EJ, Berry JD, Borden WB, Bravata DM, Dai S, Ford ES, Fox CS, Franco S, Fullerton HJ, Gillespie C, Hailpern SM, Heit JA, Howard VJ, Huffman MD, Kissela BM, Kittner SJ, Lackland DT, Lichtman JH, Lisabeth LD, Magid D, Marcus GM, Marelli A, Matchar DB, McGuire DK, Mohler ER, Moy CS, Mussolino ME, Nichol G, Paynter NP, Schreiner PJ, Sorlie PD, Stein J, Turan TN, Varani SS, Wong ND, Woo D, Turner MB; American Heart Association Statistics Committee and Stroke Statistics Subcommittee. Heart disease and stroke statistics-2013 update: a report from the American Heart Association. Circulation. 2013;121:e6-e245.

3. Borlaug BA, Paulus WJ. Heart failure with preserved ejection fraction: pathophysiology, diagnosis, and treatment. Eur Heart J. 2011;32:670-679.

4. Kuznetsova T, Herbots L, López B, Jin Y, Richart T, Thijs L, González A, Herregods MC, Fagard RH, Díez J, Staessen JA. Prevalence of left ventricular diastolic dysfunction in a general population. Circ Heart Fail. 2009;2:105-112.

5. Kloch-Badelek M, Kuznetsova T, Sakiewicz W, Tikhonoff V, Ryabikov A, González A, Loster M, Thijs L, Jin Y, Malyutina S, Stolarz-Skrzypek K, Casiglia E, Díez J, Narkiewicz K, Kawecka-Jaszcz K, Staessen JA; on behalf of the European Project on Genes in Hypertension (EPOGH) Investigators. Prevalence of diastolic left ventricular dysfunction in European populations based on crossvalidated diagnostic thresholds. Cardiovasc Ultrasound. 2012;10:10.

6. Redfield MM, Jacobsen SJ, Burnett JC Jr, Mahoney DW, Bailey KR, Rodeheffer RJ. Burden of systolic and diastolic ventricular dysfunction in the community. Appreciating the scope of the heart failure epidemic. JAMA. 2003;289:194202.

7. Marrachelli VG, Monleon D, Rentero P, Mansego ML, Morales JM, Galan I, Segura R, Martinez F, Martin-Escudero JC, Briongos L, Marin P, Lliso G, Chaves FJ, Redon J. Genomic and metabolomic profile associated to microalbuminuria. PLoS One. 2014;9:e98227.

8. Cheng ML, Wang $\mathrm{CH}$, Shiao MS, Liu MH, Huang YY, Huang CY, Mao CT, Lin JF, Ho HY, Yang NI. Metabolic disturbances identified in plasma are associated with outcomes in patients with heart failure: diagnostic and prognostic value of metabolomics. J Am Coll Cardiol. 2015;65:1509-1520.

9. Tenori L, Hu XY, Pantaleo P, Alterini B, Casttelli G, Olivotto L, Bertini I, Luchinat $C$, Gensini GF. Metabolomic fingerprint of heart failure in humans: a nuclear magnetic resonance spectroscopy analysis. Int J Cardiol. 2013;168:e113e115.

10. Kang SM, Park JC, Shin MJ, Lee H, Oh J, Ryu DH, Hwang GS, Chung JH. ${ }^{1} \mathrm{H}$ nuclear magnetic resonance based metabolic urinary profiling of patients with ischemic heart failure. Clin Biochem. 2011;44:293-299.

11. Wang TJ, Gupta DK. Metabolic profiles in heart failure. Looking for unique signatures in a heterogeneous syndrome. J Am Coll Cardiol. 2015;65:15211524.

12. Zhang Z, Staessen JA, Thijs L, Gu Y, Liu Y, Jacobs L, Koeck T, Zürbig P, Mischak $\mathrm{H}$, Kuznetsova T. Left ventricular diastolic dysfunction in relation to the urinary proteome: a proof-of-concept study in a general population. Int J Cardiol. 2014; 176:158-165.

13. Liu YP, Gu YM, Thijs L, Knapen MHJ, Salvi E, Citterio L, Petit T, Delli Carpini S, Zhang Z, Jacobs L, Jin Y, Barlassina C, Manunta P, Kuznetsova T, Verhamme P, Struijker-Boudier HA, Cusi D, Vermeer C, Staessen JA. Inactive matrix Gla protein is causally related to adverse health outcomes: a Mendelian randomization study in a Flemish population. Hypertension. 2015;65:463-470. 
14. Gottdiener JS, Bednarz J, Devereux R, Gardin J, Klein A, Manning WJ, Morehead A, Kitzman D, Oh J, Quinones M, Schiller NB, Stein JH, Weissman NJ. American Society of Echocardiography recommendations for use of echocardiography in clinical trials. A report from the American Society of Echocardiography's Guidelines and Standard Committee and the Task Force on Echocardiography in Clinical Trials. J Am Soc Echocardiogr. 2004;17:1086-1119.

15. Kuznetsova T, Codd V, Brouilette S, Thijs L, González A, Jin Y, Richart T, van der Harst P, Díez J, Staessen JA, Samani NJ. Association between left ventricular mass and telomere length in a population study. Am J Epidemiol. 2010;172:440-450.

16. Griffin JL, Atherton H, Shockcor J, Atzori L. Metabolomics as a tool for cardiac research. Nat Rev Cardiol. 2011;8:630-643.

17. Shah SH, Kraus WE, Newgard CB. Metabolomic profiling for the identification of novel biomarkers and mechanisms related to common cardiovascular diseases: form and function. Circulation. 2012;126:1110-1120.

18. Nicholson JK, Foxall PJ, Spraul M, Farrant RD, Lindon JC. $750 \mathrm{MHz} 1 \mathrm{H}$ and $1 \mathrm{H}-13 \mathrm{C}$ NMR spectroscopy of human blood plasma. Anal Chem. 1995;67: 793-811.

19. O’Brien E, Asmar R, Beilin L, Imai Y, Mallion JM, Mancia G, Mengden T, Myers M, Padfield P, Palatini P, Parati G, Pickering T, Redón J, Staessen J, Stergiou G, Verdecchia P; on behalf of the European Society of Hypertension Working Group on Blood Pressure Monitoring. European Society of Hypertension recommendations for conventional, ambulatory and home blood pressure measurement. J Hypertens. 2003;21:821-848.

20. Matthews DR, Hosker JP, Rudenski AS, Naylor BA, Treacher DF, Turner RC. Homeostasis model assessment: insulin resistance and $\beta$-cell function from fasting glucose and insulin concentrations in man. Diabetologia. 1985;28:412419.

21. Levey AS, Stevens LA, Schmid CH, Zhang Y, Castro AF III, Feldman HI, Kusek JW, Eggers P, Van Lente F, Greene T, Coresh J; for the CKD-EPI (Chronic Kidney Disease Epidemiology Collaboration). A new equation to estimate glomerular filtration rate. Ann Intern Med. 2009;150:604-612.

22. Expert Committee on the Diagnosis and Classification of Diabetes Mellitus. Report of the expert committee on the diagnosis and classification of diabetes mellitus. Diabetes Care. 2003;26(suppl 1):S5-S20.

23. Robin X, Turck N, Hainard A, Tiberti N, Lisacek F, Sanchez JC, Müller M. pROC: an open-source package for $\mathrm{R}$ and $\mathrm{S}+$ to analyze and compare ROC curves. BMC Bioinformatics. 2011;12:77.

24. Brutsaert DL, Sys SU, Gillebert TC. Diastolic failure: pathyphysiology and treatment and therapeutic implication. J Am Coll Cardiol. 1993;22:318-325.

25. Czibik G, Steeples V, Yavari A, Ashrafian H. Citric acid cycle intermediates in cardioprotection. Circ Cardiovasc Genet. 2014;7:711-719.
26. Reitzer LJ, Wice BM, Kennell D. Evidence that glutamine, not sugar, is the major energy source for cultured HeLa cells. J Biol Chem. 1979;254:2669-2676.

27. Dello SA, Neis EP, de Jong MC, van Eijk HM, Kicken CH, Olde Damink SW, Dejong $\mathrm{CH}$. Systematic review of ophthalmate as a novel biomarker of hepatic glutathione depletion. Clin Nutr. 2013;32:325-330.

28. Soga T, Baran R, Suematsu M, Ueno Y, Ikeda S, Sakurakawa T, Kakazu Y, Ishikawa T, Robert M, Nishioka T, Tomita M. Differential metabolomics reveals ophthalmic acid as an oxidative stress biomarker indicating hepatic glutathione consumption. J Biol Chem. 2006;281:16768-16776.

29. Ito T, Schaffer S, Azuma J. The effect of taurine on chronic heart failure: actions of taurine against catecholamine and angiotensin II. Amino Acids. 2014;46:111-119.

30. Azuma J, Sawamura A, Awata N, Ohta H, Hamaguchi T, Harada H, Takihara K, Hasegawa H, Yamagami T, Ishiyama T, Iwata H, Kishimoto S. Therapeutic effect of taurine in congestive heart failure: a double-blind crossover trial. Clin Cardiol. 1985;8:276-282.

31. Jeejeebhoy F, Keith M, Freeman M, Barr A, McCall M, Kurian R, Mazer D, Errett L. Nutritional supplementation with MyoVive repletes essential cardiac myocyte nutrients and reduces left ventricular size in patients with left ventricular dysfunction. Am Heart J. 2002;143:1092-1100.

32. Beyranvand MR, Khalafi MK, Roshan VD, Choobineh S, Parsa SA, Piranfar MA. Effect of taurine supplementation on exercise capacity of patients with heart failure. J Cardiol. 2011;57:333-337.

33. Li P, Yin YL, Li D, Kim SW, Wu G. Amino acids and immune function. Br J Nutr. 2007;98:237-252.

34. Shi W, Meininger CJ, Haynes TE, Hatakeyama K, Wu G. Regulation of tetrahydrobiopterin synthesis and bioavailability in endothelial cells. Cell Biochem Biophys. 2004;41:415-434.

35. Barter PJ, Nicholls S, Rye KA, Anantharamaiah GM, Navab M, Fogelman AM. Antiinflammatory properties of HDL. Circ Res. 2004;95:764-772.

36. Repetto MG, Ossani G, Monserrat AJ, Boveris A. Oxidative damage: the biochemical mechanism of cellular injury and necrosis in choline deficiency. Exp Mol Pathol. 2010;88:143-149.

37. Zordoky BN, Sung MM, Ezekowitz J, Mandal R, Han B, Bjorndahl TC, Bouatra S, Anderson T, Oudit GY, Wishart DS, Dyck JR, Alberta H. Metabolomic fingerprint of heart failure with preserved ejection fraction. PLoS One. 2015;10:e0124844.

38. Krim SR, Campbell P, Lavie CJ, Ventura H. Micronutrients in chronic heart failure. Curr Heart Fail Rep. 2013;10:46-53.

39. Knez J, Winckelmans E, Plusquin M, Thijs L, Cauwenberghs N, Gu Y, Staessen JA, Nawrot TS, Kuznetsova T. Correlates of peripheral blood mitochondrial DNA content in a general population. Am J Epidemiol. 2016;183:138-146. 


\title{
Journal of the American Heart Association \\ OPEN ACCESS f
}

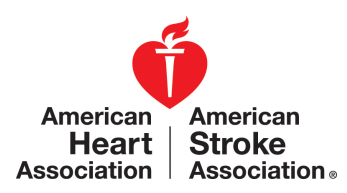

\section{Diastolic Left Ventricular Function in Relation to Circulating Metabolic Biomarkers in a General Population}

Zhen-Yu Zhang, Vannina G. Marrachelli, Lutgarde Thijs, Wen-Yi Yang, Fang-Fei Wei, Daniel Monleon, Lotte Jacobs, Tim Nawrot, Peter Verhamme, Jens-Uwe Voigt, Tatiana Kuznetsova, Josep Redón and Jan A. Staessen

\author{
J Am Heart Assoc. 2016;5:e002681; originally published March 29, 2016; \\ doi: 10.1161/JAHA.115.002681 \\ The Journal of the American Heart Association is published by the American Heart Association, 7272 Greenville Avenue, \\ Dallas, TX 75231 \\ Online ISSN: 2047-9980
}

The online version of this article, along with updated information and services, is located on the World Wide Web at:

http://jaha.ahajournals.org/content/5/3/e002681

Subscriptions, Permissions, and Reprints: The Journal of the American Heart Association is an online only Open Access publication. Visit the Journal at http://jaha.ahajournals.org for more information. 